\title{
"Play it again, Sam". A differentiating view on repeated exposure to narrative content in media
}

\author{
JELLA HOFFMANN
}

\begin{abstract}
Whereas repeated exposure to communication is a widespread phenomenon, it has so far received little attention in communication research. This article takes a step towards describing, differentiating, and explaining repeated exposure to communication. It discusses different forms of repeated exposure and then focuses on repeated exposure to narrative films. It explores possible motivations for reusing the same media content again and again, while taking processes of repeated exposure as well as situational and personal variables into account. The initially theoretical considerations are then supported, expanded, and specified both by existent empirical evidence and findings from a focus group study. Finally, further questions about repeated exposure to narrative content in media are discussed.
\end{abstract}

Keywords: media use, selectivity, repeated exposure, reception processes, narrative content, films

Someone who knows the Hollywood classic Casablanca will perhaps notice that "Play it again, Sam" is a quote from it. Someone who knows it better - for example after seeing it several times - will perhaps recognize that it is in fact a misquote that has become much more famous than the original "Play it, Sam". In 1971, Woody Allen even chose "Play it again, Sam" as a film title. But Casablanca is not only quoted and misquoted regularly, it is also watched again and again, being one of the most popular films ever. In 1998, it was selected by the American Film Institute as the second best American movie of all time. Casablanca is one of those evergreens that many people enjoy even when they see it for the second, third, or fourth time, and they therefore often intentionally seek these repeated exposures. 
Of course, not all of us have watched Casablanca repeatedly, and some might have never seen it at all. But nevertheless, most of us have probably seen a film and enjoyed it more than once. And this 'playing again' is today easier than ever. Even though the media industry produces millions of new books, movies, series etc., a remarkable and very successful share of overall media supply is reprints, reruns, and recycled or recorded versions of already existing content. As far as audio-visual content is concerned, not only blockbusters and Hollywood classics such as Casablanca but virtually any film or TV production is available on VHS or DVD. In Germany for example, there were 22,000 DVDs on the market by 2004 (BVV, 2005b). In addition, content recycling also occurs in the TV market. Whereas in the 1970s only one in ten minutes of TV-time was filled with reruns, since the 1990s, at least every third minute contains reused programs (Wehn, 2002: 118). Intervals between the first run and the second run become shorter and shorter (Wehn, 2002: 119). In fact, in most cases, the second, third, or fourth rerun is a constant in production calculations (Wehn, 2002: 74; Weispfenning, 2003: 166). And because TV reruns have become so common, in 1999, U.S. networks even stopped labeling them as reruns in, for instance, program guides (Weispfenning, 2003: 167). As a new trend more and more TV series are also available on DVD as boxed sets (Rosenbach, 2005). And apparently, in spite of a growing and theoretically unlimited collection of new products, audiences seem to like reruns and often intentionally use the same content again and again. In Germany, the overall turnover of video and DVD sales more than doubled since 1999 and now exceeds box-office results by over 100 per cent (Turecek, Grajczyk, and Roters, 2005: 582) ${ }^{1}$. Accordingly, 65 per cent of German households posses a DVD device (recorder or player) and 73 per cent own a VHSrecorder (Turecek et al., 2005: 583). Moreover, looking at the TV market, ratings of reruns are still high or sometimes even higher than first run ratings (Furno-Lamude and Anderson, 1992; Wehn, 2002: 120). For instance, Casablanca has been broadcast in Germany several times and still ends up with market shares between 12 and 14 per cent (years 1998, 1999 and 2003; AGF/GfK-Fernsehforschung). And as the two other exemplary films Dirty Dancing and Die Hard in table 1 show, there is sometimes only a marginal decrease in viewers, even after several reruns.

The same holds true for evergreens such as the James Bond series, the Sissi series or several Hitchcock classics. But by far the 'greenest evergreen' - at least in Germany - is the British comedy Dinner for One. Since 1991 it has been broadcast 164 times and has been watched by a total 143.6 million viewers (AGF/GfK-Fernsehforschung). 
Table 1. Ratings of television reruns in Germany.

\begin{tabular}{|c|c|c|c|c|c|}
\hline \multicolumn{3}{|c|}{ Dirty Dancing } & \multicolumn{3}{|c|}{ Die Hard } \\
\hline \multicolumn{2}{|l|}{ Channel } & \multirow{2}{*}{$\begin{array}{l}\text { Viewers (*million) } \\
1,21\end{array}$} & \multicolumn{2}{|c|}{ Channel } & \multirow{2}{*}{$\frac{\text { Viewers }(* \text { million })}{2,32}$} \\
\hline RTL II & 11.04 .93 & & PRO7 & 04.04 .92 & \\
\hline RTL & 03.07 .94 & 4,33 & PRO7 & 05.02 .94 & 3,30 \\
\hline RTL II & 09.09 .95 & 2,02 & PRO7 & 21.01 .95 & 4,99 \\
\hline PRO7 & 25.10 .96 & 4,23 & PRO7 & 30.03 .96 & 3,62 \\
\hline RTL & 24.12 .98 & 3,24 & SAT.1 & 29.03 .97 & 3,66 \\
\hline RTL & 31.03 .99 & 4,39 & SAT.1 & 31.05 .98 & 2,48 \\
\hline PRO7 & 31.01 .03 & 4,38 & SAT.1 & 21.05 .99 & 2,97 \\
\hline PRO7 & 19.11 .03 & 4,07 & SAT.1 & 01.01 .00 & 2,63 \\
\hline RTL & 09.06 .04 & 4,44 & PRO7 & 10.03 .01 & 3,21 \\
\hline \multirow[t]{4}{*}{ SAT.1 } & 26.03 .05 & 3,08 & PRO7 & 31.03 .02 & 2,44 \\
\hline & & & PRO7 & 01.03 .03 & 2,76 \\
\hline & & & SAT.1 & 26.12 .03 & 3,10 \\
\hline & & & PRO7 & 25.03 .05 & 1,82 \\
\hline
\end{tabular}

Source: AGF/GfK Fernsehforschung

Whereas repeated exposure to communication seems to be a widespread and by far not a new phenomenon ${ }^{2}$, little attention has been paid to it in communication research, partly because it is rarely seen as different from first exposure. But the few existing studies strongly suggest that repeated exposure is not only highly enjoyable but also caused by somewhat different motivations than first exposure (Tannenbaum, 1985; Furno-Lamude and Anderson, 1992). Accordingly, this article takes a step towards describing, differentiating, and explaining repeated exposure to communication. It discusses different forms of repeated exposure before focusing on repeated exposure to narrative films and the possible motivations for reusing the same media content again and again. In addition, I will focus on processes of repeated exposure as well as potentially influential situational and personal variables. Every section therefore starts with theoretical considerations and - if existent - empirical evidence which are then supported, expanded, and specified by findings from a qualitative study carried out using focus groups. For this study four focus groups (one older group, one younger group, two mixed groups) discussed repeated exposure using an interview guide that had been constructed based on several perspectives (e. g., frequency of repeated exposure to different media and content, reused films, genre and features of reused films, motives, processes and modes of reception). In sum, 27 personally contacted people of all ages (between 22 and 71 years old), all levels of education, and of different occupations participated in the study. Ten of them were male and 17 were female. The videotaped discussions were transcripted, summarized, and categorized using the in- 
terview guide, so that the results could be structured according to the theoretically defined topics. Finally, the last section will provide a brief summary and discusses further questions about repeated exposure to narrative content in media ${ }^{3}$.

\section{Differentiating repeated exposure}

Even though repeated exposure seems to be a universal phenomenon, the probability and frequency as well as motivations and reception processes may vary depending on the medium, the content, and the mode of selection.

The medium. Repeated exposure can occur with every medium. Children, for example, enjoy hearing the same bed-time stories or radio plays, while adults reread books, buy, and borrow DVDs, as well as watch television reruns. However, repeated exposure is more probable and frequent with media that are permanent (books, CDs, DVDs), easily recordable (TV) or in themselves repetitive (TV) than with relatively transient media (radio, newspapers, internet) 4 . According to the focus groups, especially audio-visual media (films and series seen at a movie theater, on TV, or on DVD) qualify for repeated exposure. Books are very rarely read more than once, mostly because reading a book takes more time. However, most of the participants can think of books they would like to reread and remember rereading books during childhood. In addition, radio plays, comics, and plays were also mentioned as suitable for repeated exposure.

The content. Although any media content can be used more than once, some seems more suitable for repeated exposure than others. Informational content may be reused to refresh knowledge or to catch up on details, but topical information such as the news will rarely be used more than once ${ }^{5}$. In contrast, relatively timeless content such as stories or music seems to be predestined for multiple use ${ }^{6}$. DVD-sales and TV ratings indicate that fictional narratives account for the bulk of repeated exposures (besides music) (BVV, 2005a/b) ${ }^{7}$. This may be because the primary aims of repeated exposure are entertainment and enjoyment, which are often achieved by watching narrative fiction. In addition, experiencing narratives does not seem to lose its attractiveness with multiple use because its enjoyment does not depend on newness. In view of the specific content inherent to certain genres, one could assume that genres such as suspense or mystery, which are based on uncertainty, curiosity, and surprise, are not as suitable for repeated exposure as other genres. Results of the focus groups back the notion of repeated exposure mainly 
occurring with narrative content and almost not at all with topical information. However, according to the specific products the participants named, e.g., Ice Age, The Lord of the Rings, The Sixth Sense, Sissi, Dinner for One, Ben Hur, Der Schuh des Mannitou, repeated exposure covers all genres. In view of certain features that qualify for reuse, participants mentioned many different aspects: humor, suspense, music, style, characters, and so on. The interview with the focus groups also revealed interaction between medium and content, since besides several other genres, mainly film comedies were mentioned as suitable for repeated exposures, while participants also reported that suspenseful, solemn, or profound books are reread far more frequently than humorous books. This could be related to the social situation of repeated exposures (group versus alone, see below).

Mode of selection. Repeated exposure can occur accidentally, for instance, when one habitually watches TV with no regard to content, or because one does not realize that one already knows the content. But repeated exposure can also be planned; i. e., when one possesses at least partial knowledge of and consciously chooses the already familiar content.

As the previously introduced forms of repeated exposure cannot be discussed comprehensively, I will now focus on planned repeated exposure to narrative films.

\section{Motives for repeated exposure}

In general, repeated exposure, like first exposure, can be caused by any motivation known from the classical uses and gratifications research. Examples of such motivations are: relaxation, companionship, habit, entertainment, social interaction, arousal, and information (for an overview see e.g., Rubin, 2002). Unlike first exposure, however, it enables users to almost perfectly predict the effect or resulting gratification (gratifications obtained) and thus permits choices that optimally match actual needs (gratifications sought). Thus, repeated exposure is a perfect means for mood management (see e. g., Zillmann, 1988a, 1988b), because mood effects of already known content can be calculated much more easily than effects of unknown content. Repeated exposure therefore facilitates selection and offers a safe and reliable form of entertainment without the risk of a confrontation with unfamiliar content such as new plots or characters (Tannenbaum, 1980: 128). Additionally, through its familiarity, repeated exposure allows for the human need for security and feelings of control which are said to be important prerequisites for experiencing entertainment (Früh, 2002; Früh, Wünsch, and Klopp 2004). 
During repeated exposure, passive control through predictability - in contrast to active control through taking action - is at a maximum. In this context, according to the mere exposure effect (e.g. Zajonc, Crandall, Kail, and Swap 1974), familiarity or redundancy could also be a reason for preference in itself, because we simply like what we know. The mere exposure effect can thus also account for multiple exposures (more than one repetition) because if one knows something even better one may also like it even better. A second general motive, relaxation, could also play an important role in repeated exposure. The redundancy of familiar content requires less cognitive effort than the processing of new information. As 'cognitive misers', recipients may not be willing to invest too much cognitive capacity in media use and might therefore experience repeated exposure as more relaxing (Barwise, Ehrenberg, and Godhart, 1982: 28; Tannenbaum, 1985: 236) ${ }^{8}$. In addition, by requiring less concentration and attention than the first exposure, repeated exposure can be easily combined with other activities such as conversation or chores. Moreover, social interaction could be a motivating factor for repeated exposures, e.g., if one is more familiar with something, it is easier to talk about it, or perhaps repeated exposure is in itself a social (group) experience. Considering the multiple use of narrations another plausible motivating factor comes to mind, i. e., the preference for certain characters or actors, and parasocial relations. Interestingly, in their study, Furno-Lamude and Anderson (1992) found that parasocial attraction is, as well as pure pastime, of no higher importance as a motive for repeated exposure as it is for first exposure. Though their study is confined to reruns of U.S. TV series, Furno-Lamude and Anderson detected additional motives that become particularly evident through repeated exposure: nostalgia and recall. Nostalgia means that repeated exposure can satisfy the desire to remember the past, to feel how one felt when one first saw a film (Furno-Lamude and Anderson, 1992: 370; see also Mikos, 2004: 41; Weispfennig, 2003). Under the label 'recall' they list aspects such as remembering the end or parts one forgot and the statement "I look for different things when I see it again" (Furno-Lamude and Anderson, 1992: 370).

The findings of the focus groups mainly confirm the above-mentioned considerations about motives for repeated exposure. Thus participants stress the low risk of bad surprises when reusing previously enjoyed content and the mood management function:

Just if, when watching a certain film, I know that I feel good while watching it, I would rather watch that film than a different film that I do not know (female student, 24 years old) ${ }^{9}$. 
In addition, relaxation and the possibility of multitasking due to a relatively low cognitive demand are often mentioned as reasons for repeated exposure. In contrast to Furno-Lamude and Anderson's (1992) findings, participants of the focus groups name parasocial relations as well as identification and empathy with the characters as a motivating factor. However, some of the statements do not clearly indicate if parasocial relations are a motive in general or a special motive for repeated exposure. In this case, more definitive evidence will have to be collected. As other important motives, the participants name aspects of nostalgia, such as remembering one's childhood, a certain period of life, or places one knows and likes. In addition, certain events as well as the social situation are seen as reasons for repeated exposure (e. g., Dinner for One as an obligation on New Year's Eve). Finally, the participants regularly mention aspects of 'recall' such as remembering forgotten parts or gaining a deeper understanding of the content. More specifically, they often cite the possibility of fantasizing or the ability to concentrate on certain details as additional reasons for repeated exposure ${ }^{10}$. These last aspects, however, refer more to the process of re-exposure than to its effects. They thus introduce an idea that deserves more theoretical consideration and especially empirical work; i.e., reception processes as motivating factors for repeated exposure.

\section{Processes of repeated exposure}

In agreement with Tannenbaum (1985: 225), this study strongly supports the notion of repeated exposure as generally an intrinsically motivated activity (autotelic) (see Cupchik and Kemp, 2000). Thus, recipients reuse narrative media not only as a safe and reliable means to satisfy needs of relaxation, but also because they enjoy and therefore seek the reexperiencing in itself. As far as affective experiences are concerned, virtually any first exposure emotion can be re-experienced during repeated exposures (Tannenbaum, 1985: 239; Früh, 2005). Tannenbaum (1985: 239) found that, according to physiological measurement, recipients show, in comparison to first exposure, the same but less intensive reaction patterns during repeated exposures. When it comes to more extreme responses, e. g., to a horror film, or the anticipation of future actions or events, these can also enhance emotional reactions during re-exposure through excitation transfer (Cantor, Ziemke, and Sparks, 1984; see also e. g., Bryant and Miron, 2003). Although repeat viewers already know the outcome of the plot, they still seem to feel suspense during re-exposure ('paradox of suspense'; see Brewer, 1996; Carroll, 1996; Gerrig, 1989; Yanal, 1996). In addition to this potentially enjoyable re-experiencing of emotion similar to first exposure, I would like to suggest that 
repeated exposure also allows for cognitive experiences that may be different from the first exposure. Already knowing the plot of a narrative facilitates information processes and thus provides a relaxing experience. But it also releases the recipient from his sheer narrative lust and enables him to attend to aspects other than the course of events. Depending on the content and its complexity, repeaters can thus notice hidden jokes, look for early clues of the plot development, search for mistakes or mishaps, concentrate on certain characters, analyze dialogues, or focus on stylistic elements such as setting, music, color, and editing. During repeated exposure, recipients are freer to choose their perspective or to try several 'reception modalities' (Suckfüll, 2004). Accordingly, modalities which express a cognitively playful strategy of reception such as 'play' (e. g., the viewer makes up ones own development of the plot), 'narration' (a deep engagement with the plot and narrative structures), or 'production' (e.g., one imagines oneself as the director) (Suckfüll, 2004) should be more frequent with repeated exposure than with first exposure $^{11}$. Results of the focus groups confirm and specify the importance of processes of re-exposure.

As far as affective experiences are concerned, some of the participants mentioned the mood management function not only as reaching a desired mood state after repeatedly seeing a film, but also as re-experiencing a certain mood during re-exposure. Thus, emotional experiences must be repeatable and viewers are apparently aware of the pervasive emotional impact of certain films. In view of suspense there were different opinions; some participants said that the intensity of suspense did not change with repeated exposure, but most of them saw suspense as decreasing with every exposure. In contrast, humor seems to be much more resistant to wearing out as a result of repetition. Only a few participants saw a fading attraction of jokes or funny scenes. Most of them were of the opinion that a humorous film can be laughed at during repeated exposures as well as during first exposure. Some films even became funnier with repeated exposures. One explanation could be the enhancing effect of pleasant anticipation previous to certain funny scenes (excitation transfer). Another reason explicitly named by the participants is that sometimes one has to read between the lines to get the joke. This notion already touches upon the idea of the specific cognitive experiences that might add to the enjoyment of repeated exposures. Indeed, the focus group participants often implied new cognitive experiences during reexposure as well as changes in modes of reception in comparison to first exposure.

For most of them re-exposure comes along with a deeper and more conscious understanding of the plot and the meaning of it (cf. they would use the reception mode known as 'narration'). In addition, all 
participants reported looking for details, hidden jokes, and early clues of the plot development. This was particularly evident with films that have a surprise ending (e.g., The Sixth Sense, The Village, The Others), which can then be analyzed in view of coherence and predictability, i. e., could the recipients see it coming.

It is like a puzzle. First, it is raw pieces because I can not take in that much at a time. Afterwards it becomes more subtle, more detailed and that's why I can see it again and again (female homemaker, 62 years old).

I like repeatedly watching films, if I discover new details in them every time I see it that I did not recognize before. For example with The Godfather I discovered something new every time I watched it (female student, 24 years old).

Some of the participants also said, that, especially during the third, fourth, fifth etc. exposures, they find pleasure in searching for mistakes or mishaps (e.g., Humphrey Bogart alias Rick in Casablanca is completely soaked by the rain in one shot, only to be perfectly dry in the next; cf. reception mode 'production') ${ }^{12}$. Another common cognitive perspective seems to be looking forward to and concentrating on certain dialogues, often with the side effect of learning them by heart. Some of the participants finally reported fantasizing beyond the explicit plot (cf. reception mode 'play').

In sum, the focus group study strongly indicates that emotional as well as cognitive processes during re-exposure are important factors for the enjoyment of repeated exposure and are thus also motivating factors. During repeated exposures recipients can re-experience first exposure emotions but can also find new cognitive experiences. Much more than during first exposure, the repeated exposures allows them to choose between perspectives as well as experiment with alternative reception modes. The finding that, according to the focus groups, cognitive experiences seem to be that important, on the one hand supports the idea that cognitively oriented reception modes play a vital role in repeated exposures. But on the other hand, one must realize that the focus on cognitions could also have at least partly resulted from the discussion approach, which requires thinking about, rationalizing, and verbalizing media behavior and might therefore have favored cognitive aspects.

\section{Situational and personal variables}

It remains to be said that several additional variables can influence the probability and frequency of occurrence as well as the motivations for 
and experiencing of repeated exposure. The most important variables are the following.

Situational variables. As mentioned above, repeated exposure can be accidental or planned. One could assume, for instance, that a search for new cognitive experiences is more probable with planned repeated exposure than with accidental re-exposures. In addition, the experience of reexposure can vary with locations, for example, repeated exposures to a film at home can be very different from exposures at the movies. Repeated exposure also depends heavily on the social situation, e. g., if you watch your favorite tearjerker all on your own or meet for a Star Wars night with your friends. In the latter case, the social experience alone can be a strong motive for repeated exposure. The findings of the focus group study reflect the theoretical difference between accidental re-exposure and planned re-exposure. Whereas the location of repeated exposures was not explicitly discussed, participants stressed the social situation as a vital factor for repeated exposures. They regarded repeated exposure mainly as a group experience, though repeated exposure on one's own can be enjoyable as well. In general, participants find it important that co-viewers are likeminded and share their opinion of the film:

The Lord of the Rings I can only watch with friends. If there are any girls around, there is always a 'how unrealistic' ..." (male employee, 29 years old).

Especially when it comes to humorous content, repeated exposure is more enjoyable in a group. Also important as a group experience are repeated exposures that are traditionally linked with certain events. Thus almost all the participants knew that watching, for instance, Ben Hur at Easter, Sissi during Christmas, or Dinner for One on New Year's Eve were typical family rituals.

Personal variables. The frequency and enjoyment of repeated exposure may vary with age, sex, education, and so forth. (e. g., Litman and Kohl, 1992). For example, one could argue that younger people always look for new stimuli and therefore might find repeated exposures boring. Or one could assume that more educated people with potentially higher cognitive capacities enjoy new content more than already known stimuli. Accordingly, Litman and Kohl (1992) found that users of TV reruns are rather low-educated. One the other hand, higher educated people might perhaps place more value on the cognitive modes of reception and therefore seek re-exposure under new perspectives. In that context, there could also be relations between sex and preferred modes of reception. 
For example, Suckfüll found that playful reception strategies such as 'play' or 'production' are more often used by male recipients (see Suckfüll, 2004: 150). Because of its qualitative approach, the focus group study can only reveal tendencies regarding personal differences. In general, repeated exposure seems to be a phenomenon beyond age, sex, and education. Merely the 'heavy-repeaters' tend to be rather young. Besides differences along demographical lines, there could be relations to traits such as openness to experience (e. g., Eysenck, 1955), sensation and novelty seeking (Zuckermann, 1971, 1979), need for cognition (Cacioppo and Petty, 1982) etc. or to one's preferred reception modalities (Suckfüll, 2004). Since personality differences could not be distinctly discussed in the focus groups, they remain to be analyzed in further studies. But participants indicated that they regard enthusiasm and imagination as a prerequisite for enjoying repeated exposures to narrative films.

\section{Conclusion and outlook}

This article presented repeated exposure as a widespread phenomenon and provided a differentiating view on repeated exposure to communication. Along theoretical considerations and with the help of a focus group study, it could be shown that repeated exposures probably vary with the medium, the specific content, and the mode of selection. In addition to any motivations known from $U$ and $G$ research, repeated exposure draws from additional motives including for instance a desire to remember the past. Another important factor seems to be the process of reexposure itself. Thus, repeaters enjoy the re-experiencing of emotions as well as the freedom to approach the content from various perspectives and to experiment with different reception modes that lead to new cognitive experiences. Finally, repeated exposure, its frequency, quality, and enjoyment could be related to personal variables such as demographics, and especially to dimensions of personality. In order to prove and specify the theoretical assumptions and qualitative empirical findings, a quantitative survey is now being conducted. It includes a quota sample of 200 subjects in a split ballot design with similar but different questionnaires referring to first or general exposure and repeated exposure respectively.

Though the theoretical considerations as well as the qualitative study mainly focus on planned repeated exposure to narrative films, some aspects could be transferred to other media, content, or modes of selection. For example, books may be reread for partly the same reasons, just as films or TV-documentaries may be as well watched a second time to get a deeper understanding of it. Even if repeated exposures are not intended, for instance, emotional experiences can resemble first exposure experiences. But as the focus groups already indicated there may also be 
differences. For example, rereading books will rarely be a group experience.

Beside the question of the transferability of these results, a lot of other topics, both in view of the aforementioned aspects and beyond, remain ${ }^{13}$. For example, in the context of repeated exposure there may occur several other phenomena such as the creation of archives and the collection of content, which are then never touched a second time. Moreover, one could ask in what way repeated exposures to the very same contents differ from other repetitive patterns of media use (e. g., repeat viewing, series viewing). In addition, processes and experiences of re-exposure should be studied more thoroughly and online, for instance, with the help of RTR-measurement (real time response, see e. g., Vorderer, 1994). Emotional aspects of re-exposure may then perhaps be more evident and measured more adequately than in a focus group study that depends on verbalizing and thus rationalizing media use. Besides the named aspects such as suspense or humor, there are other interesting factors of narrative experience that may change with multiple exposures. For example, does the feeling of presence or transportation or absorption increase because of a better knowledge of the story, its spatial and temporal relations? Or does it decrease because repeated exposures require less concentration and attention, which in turn may hinder presence and absorption? Another interesting topic is the social or quasi-social qualities repeated exposures apparently have. Why is repeated exposure in groups so enjoyable? What roles do the virtual community and the imagination of other repeaters play? In what way is repeated exposure related to the emerging of cult? In addition, it might be worthwhile to study the postexposure communication and integration of ideas or elements of a film into everyday life as well as its impact on potential re-exposures. For example, using film quotes or repeatedly listening to the soundtrack might lead to a self-enhancement effect and enforce the tendency to reuse this very film. In that context, the question arises: If a film is once drawn into a potentially self-enhancing spiral can it be repeatedly used and enjoyed forever? Or is there a point of no return, where repeated exposure looses its attractiveness? If yes, when does it happen and why?

This list of further topics and unanswered questions is only a small selection and by no means exhaustive. Nevertheless, it clearly shows that a lot more theoretical and empirical work is needed to completely describe and explain why and how people use and enjoy the same content again and again. Though Tannenbaum took the first important steps towards studying this phenomenon in his article "Play it again, Sam" more than 30 years ago, communication research in view of repeated exposure is still far from being repetitive. 


\section{Notes}

1. In 2004, 103.1 million copies were sold in Germany, not to mention the estimated 106 million illegally recorded DVDs and CDs (Turecek et al., 2005: 582).

2. For example, in the past, books were rare and expensive and thus they were read again and again. In contrast, repeated exposures as it is described here can be regarded as mainly voluntary.

3. I would like to thank all reviewers for their fruitful comments.

4. In contrast to 'repeat-viewing' (Barwise et al., 1982) repeated exposure refers to the multiple use of the same film or episode, not the exposure to following episodes of a series.

5. One exception may be news reports that are fused into reviews.

6. Music is a content that is almost exclusively used repeatedly, and repeated exposure often leads to an increase in appreciation by the listener.

7. A narrative presents "a chain of events in cause-effect relationship occuring in time and space" (Bordwell and Thompson, 1993: 65).

8. For a discussion of the mental effort while watching television see e.g., Weidenmann (1989), Salomon (1988).

9. Quotes coming from the focus group study have been translated by the author.

10. In his theoretical consideration, Tannenbaum also mentions fantasy as an aspect of repeated exposure (1985: 239).

11. Being repetitive and intrinsically motivated, repeated exposure strongly resembles play (see e. g., Oerter, 1999; Vorderer, 2001: 245-246). Therefore, media like computer or video games that are made for play are at the same time predestined for repeated exposures.

12. You can even find special websites for this, for example, www.moviemistakes.com.

13. I would like to thank the participants of the Conference on Media Use and Selectivity in Erfurt, January 2006, for their fruitful comments.

\section{References}

Barwise, T. P., Ehrenberg, A. S., and Godhart, G. J. (1982). Glued to the box? Patterns of TV repeat-viewing. Journal of Communication, 32, 22-29.

Bordwell, D. and Thompson, K. (1993). Film art: An introduction. New York: McGraw Hill.

Brewer, W. F. (1996). The nature of narrative suspense and the problem of rereading. In P. Vorderer, H. J. Wulff, and M. Friedrichsen (Eds.), Suspense: Conceptualizations, theoretical analysis and empirical explorations (pp. 107-127). Mahwah, NJ: Lawrence Erlbaum.

Bryant, J. and Miron, D. (2003). Excitation transfer theory and three-factor theory of emotion. In J. Bryant, D. R. Roskos-Ewoldson, and J. Cantor (Eds.), Communication and emotion (pp. 31-59). Mahwah, NJ: Lawrence Erlbaum.

Bundesverband Audiovisuelle Medien e. V. (BVV) (2005a). Umsatzentwicklung im Videomarkt 1999-2004. Available (consulted 26 July 2005) at http://www.bvvmedien.de/facts/umsatz.html

Bundesverband Audiovisuelle Medien e. V. (BVV) (2005b). DVD-Kaufmarkt 2004. Available (consulted 26 July 2005) at http://www.bvv-medien.de/facts/toptit.html

Cacioppo, J. T. and Petty, R. E. (1982). The need for cognition. Journal of Personality and Social Psychology, 42, 116-131.

Cantor, J., Ziemke, D., and Sparks, G. G. (1984). Effect of forewarning on emotional responses to a horror film. Journal of Broadcasting, 28, 21-31. 
Carroll, N. (1996). The paradox of suspense. In P. Vorderer, H. J. Wulff, and M. Friedrichsen (Eds.), Suspense: Conceptualizations, theoretical analysis and empirical explorations (pp. 71-91). Mahwah, NJ: Lawrence Erlbaum.

Cupchik, G. C. and Kemp, S. (2000). The aesthetics of media fare. In D. Zillmann and P. Vorderer (Eds.), Media entertainment: The psychology of its appeal (pp. 249265). Mahwah, NJ: Lawrence Erlbaum.

Eysenck, H. J. (1955). Dimensions of personality. London: Routledge and Kegan Paul. Früh, W. (2002). Unterhaltung durch das Fernsehen. Eine molare Theorie. Konstanz: UVK.

Früh, W., Wünsch, C., and Klopp, P. (2004). TDU-Unterhaltungsindex. Ein Instrument zur empirischen Ermittlung von Unterhaltungserleben. Medien- und Kommunikationswissenschaft, 52, 515-544.

Früh, H. (2005). Psychophysiologische Messmethoden in der Kommunikationswissenschaft: Die Erfassung von Rezeptionsemotionen am Beispiel von legitimierter Gewalt im Spielfilm: Psychophysiologische Messungen und eine Befragung im Vergleich. München: Unveröffentlichte Magisterarbeit.

Furno-Lamude, D. and Anderson, J. (1992). The Uses and Gratifications of rerun viewing. Journalism Quarterly, 69(2), 362-372.

Gerrig, R. J. (1989). Re-experiencing fiction and non-fiction. The Journal of Aesthetics and Art Criticism, 47(3), 277-280.

Litman, B.R. and Kohl, L.S. (1992). Network rerun viewing in the age of new programming services. Journalism Quarterly, 69(2), 383-391.

Mikos, L. (2004). Fernsehen, Kult und junge Zuschauer. Televizion, 17(2), 38-41.

Oerter, R. (1999). Psychologie des Spiels. Ein handlungstheoretischer Ansatz. Weinheim: Beltz.

Rosenbach, M. (2005). Versilberte Altlasten. Der Spiegel 50/2005, 194-196.

Rubin, A. M. (2002). The Uses-and-Gratifications perspective of media effects. In J. Bryant and D. Zillmann (Eds.), Media effects. Advances in theory and research (pp. 525-548). Hillsdale, NJ: Lawrence Erlbaum.

Salomon, G. (1988). Television and mental effort. A social psychological view. In J. Bryant and D. R. Anderson (Eds.), Children's understanding of television. Research on attention and comprehension (pp. 181-198). New York: Academic Press.

Suckfüll, M. (2004). Rezeptionsmodalitäten. Ein integratives Konstrukt für die Medienwirkungsforschung. München: R. Fischer.

Tannenbaum, P. H. (1980). Entertainment as vicarious emotional experience. In P. H. Tannenbaum (Ed.), The entertainment functions of television (pp. 107-131). Hillsdale, NJ: Lawrence Erlbaum.

Tannenbaum, P. (1985). "Play it again, Sam": Repeated exposure to television programs. In D. Zillmann and J. Bryant (Eds.), Selective exposure to communication (pp. 225-241). Hillsdale, NJ: Lawrence Erlbaum.

Turecek, O., Grajczyk, A., and Roters, G. (2005). Videomarkt und Videonutzung 2004. Gute Marktlage trotz Strukturwandels und Raubkopien. Media Perspektiven, $11,582-589$.

Vorderer, P. (1994). Involvementverläufe bei der Rezeption von Fernsehfilmen. In L. Bosshart and W. Hoffmann-Riem (Eds.), Medienlust und Mediennutz. Unterhaltung als öffentliche Kommunikation (pp. 333-342). München: Ölschläger.

Vorderer, P. (2001). It's all entertainment - sure. But what exactly is entertainment? Communication research, media psychology, and the explanation of entertainment experiences. Poetics. Journal of Empirical Research on Literature, Media, and the Arts, 29, 247-261.

Wehn, K. (2002). "Crime Time” im Wandel. Produktion, Vermittlung und Genreentwicklung des west- und ostdeutschen Fernsehkrimis im dualen Rundfunksystem. Bonn: ARCult-Media. 
Weidenmann, B. (1989). Der mentale Aufwand beim Fernsehen. In J. Groebel and P. Winterhoff-Spurk (Eds.), Empirische Medienpsychologie (pp. 134-149). München: Psychologie-Verlagsunion.

Weispfenning, J. (2003). Cultural functions of reruns: Time, memory, and television. Journal of Communication, 53(1), 165-176.

Yanal, R. (1996). The paradox of suspense. The British Journal of Aesthetics, 36(2), $146-158$.

Zajonc, R. B., Crandall, R., Kail, R. V., and Swap, W. (1974). Effect of extreme exposure frequencies on different affective ratings of stimuli. Perceptual and motor skills, 38, 667-678.

Zillmann, D. (1988a). Mood management trough communication choices. American Behavioral Scientist, 31, 327-340.

Zillmann, D. (1988b). Mood management: Using entertainment to full advantage. In L. Donohew, H. E. Sypher, and E. T. Higgins (Eds.), Communication, social cognition and affect (pp. 147-171). Hillsdale, NJ: Lawrence Erlbaum.

Zuckermann, M. (1971). Dimensions of Sensation Seeking. Journal of Consulting and Clinical Psychology, 36, 45-52.

Zuckermann, M. (1979). Sensation seeking: Beyond the optimal level of arousal. Hillsdale, NJ: Lawrence Erlbaum. 